\title{
Anthropology and its relevance to psychiatry
}

\author{
E. A. Roch* \\ Faculty of Public Health Medicine, Royal College of Physicians of Ireland, Ireland
}

First published online 30 August 2016

\section{Introduction}

Anthropology is the study of humankind, of how people cope with the common problems of living in different places and at different times, of the ways people organise themselves in society and the beliefs and practices they develop. It is an academic discipline which describes cultural similarities and differences. Further, anthropology aims to capture or discern the insider view. The discipline is inclusive and multidimensional in its approach, paying attention to context and complexity (Helman, 2007).

In relation to health, the subspeciality 'medical anthropology' is concerned with the comparative and holistic study of health, disease and health care systems. Further subspecialities have emerged in the United States and United Kingdom with a focus on mental health namely psychiatric anthropology, trans-cultural psychiatry and cross-cultural psychiatry.

Cultural differences are obviously relevant in our increasingly diverse society and in the globalisation of health problems and solutions. Understanding the perspectives of patients and health professionals is crucial for the successful design and operation of health services. Appreciation of patient beliefs and perspectives helps in understanding the expression of illness and response to intervention, and is essential for developing patient-centred care. Engaging patients in the self-management of illness and paying attention to complexity are especially important in the management of chronic disease which, by definition, has a prolonged course, often in conjunction with other chronic illnesses, and mostly away from the immediate care of clinicians and health services.

The value of anthropology lies in its qualitative research methodology, its characteristic concepts and approach, the resource of comparative literature and the contribution of anthropologists in the workplace.

* Address for correspondence: E. A. Roch, Faculty of Public Health Medicine, Royal College of Physicians of Ireland, 6 Kildare St, Dublin 2, Ireland.

(Email: bethannr@eircom.net)

\section{Qualitative research methods}

Anthropology is associated with qualitative research methods, in particular and traditionally with extended 'participant observation', living or working within a community or setting. While this ethnographic approach gives rich and detailed information, it has a major disadvantage in that it takes a long time. Faster methods of data capture have been developed, for example focus groups and rapid appraisal. Direct observation of human behaviour, to distinguish the rhetoric from reality, is central and uncovering the range of meaning behind quantitative data is key. While qualitative methodology is now part of the general toolbox of methods employed by researchers in different disciplines, anthropologists have a particular expertise in this type of research method.

An example of anthropological input to current health-related research projects in Ireland is Epilepsy Partnership in Care, a collaboration between academics at Maynooth University and the Royal College of Surgeons Ireland. This project aims to improve understanding of how care is delivered to those affected by complex chronic diseases, such as epilepsy (https:// www.maynoothuniversity.ie/anthropology/news / maynooth-university-collaboration-rcsi-awarded-fundingepilepsy-care-research). Through University College Dublin, there is anthropological input to the PREPARE (Platform for European Preparedness Against (Re-) emerging Epidemics) project which examines 'Structural and Behavioural/Cultural Barriers to the Rapid Implementation of Large Multi-Site Clinical Studies in Europe in response to severe Infectious Disease outbreaks' (http://www.prepare-europe.eu/PREPARENetwork/PREPARE-partners). Also, qualitative methodology is used by the Partnership for Health Equity which aims to improve access to primary health care for marginalised groups (http: / / www.ul.ie/gems / partnership-health-equity).

\section{Concepts and approach}

The anthropological approach is holistic, describing societies or cultures as integrated wholes, and society as 
a system with subsystems. The discipline examines the interrelationship between individuals and society and aims to highlight how society 'works'. It looks at the whole picture and considers all aspects of human behaviour and the complexity of the context in which it occurs. Different ways of looking at the world or 'world views' are described to show how meaning may differ depending on perspective or 'cultural relativity'. Further, it is recognised that people tend to have 'ethnographic prejudice', to believe that their perspective is 'right' and that other perspectives are 'wrong'. In relation to health, 'medical pluralism' refers to the existence of different medical traditions within a particular society and 'healer shopping' refers to the patient search for alternative therapists.

\section{Comparative literature and knowledge}

An extensive body and resource of literature has been amassed. Anthropological studies have recorded both historical and contemporary information in many different societies and cultures. In relation to health, 'culture bound' syndromes have been described which are characteristic of particular cultures but not of human society in general. Information pertinent to mental health has been collected from around the world, not only by anthropologists but also by psychiatrists working in non-western countries who have encountered and documented conditions which are unfamiliar to western trained practitioners and fall outside western diagnostic categories.

The development of anthropology in Ireland is summarised in The Anthropology of Ireland (Wilson \& Donnan, 2006), including reference to some controversial work on mental health in the 1970s. More recent research on mental health has been carried out by Jamie Saris from Maynooth University, for example his work on asylums (Saris, 1997), addiction (Saris, 2011, 2013a) and suicide (Saris, 2013b). Other local work in medical anthropology includes research on folk medicine, for example Folk Healing and Healthcare Practices in Britain and Ireland. (Moore \& McClean, 2010) and ongoing research about lay healers by Carol Barron, Dublin City University. Irish medical anthropologists have contributed to research in other countries including work on HIV treatment in South Africa (Larkan et al. 2015) and children's mental health in Nepal (Pettigrew, 2007).

\section{Anthropologists in the workplace}

Anthropologists have participated in the planning, application and evaluation of health care programmes. They act as mediators or 'cultural brokers' between health care teams and local populations to encourage community participation and ensure the acceptability of health interventions. The potential role of anthropologists in outbreaks of infectious disease was outlined by the World Health Organisation (2012) and has been highlighted in the Ebola outbreak in West Africa (Shears \& O'Dempsey, 2015). Elsewhere anthropologists have been involved with integrating mental health care with traditional healing as described in Puerto Rico (Koss-Chionino, 1999).

In Ireland anthropologist Cormac Sheehan works as Research Officer in the Mallow Primary Healthcare Centre and teaches medical students in the Department of General Practice, University College Cork. He is involved with the Crystal Project for people affected by dementia; initiatives include the establishment of a memory resource room (http://www.crystalproject. ie). In addition he manages the NEIL (Neuro Enhancement for Independent Lives) study in Mallow, a satellite of the NEIL Memory Research Unit in Trinity College Dublin; this is a large study examining cognitive health in people over the age of 50 (https:/ / www.tcd.ie/Neuroscience/neil/research/memory/). He worked with a multidisciplinary team in the prize winning EARLI Research Project which developed interventions to reduce emergency hospital admissions in the over $70 \mathrm{~s}$ (http://www.mphc.ie/about-us/ research-audit/).

Also in Ireland, Judith Pettigrew, an anthropologist and occupational therapist based in the University of Limerick, does research on patient quality of life with the Forensic Mental Health Service at national and European levels.

\section{Anthropology in Ireland}

Anthropology is a limited resource in Ireland. There is a Department of Anthropology at Maynooth University and a School of History and Anthropology at Queen's University of Belfast. However, there are anthropologists, including medical anthropologists, scattered throughout the system in both academic and healthrelated positions, some of whom trained in other countries.

In 2015 the Irish Medical Anthropology Network (IMAN) was established in order to harness and strengthen ongoing work in medical anthropology and to make anthropology more accessible to health professionals. The Anthropological Association of Ireland (AAI) website hosts an IMAN section at www.anthro pologyireland.org. It is planned to showcase current work, to encourage interdisciplinary research and to develop training materials and modules. A mailing list has been set up to circulate information of common interest to members of the network. A launch workshop was held at the AAI conference in Cork in 2015; topics 
included cultural competence, risk perceptions relating to vaccines and lay beliefs about healing. Also in 2015, medical anthropologist Susan J. Shaw spoke to members of IMAN about her 15 years experience of collaboration with community health centres in the United States.

This year members of IMAN were fortunate to have the opportunity to meet Arthur Kleinman in Ireland. Arthur Kleinman has a long, distinguished and influential career in both psychiatry and medical anthropology and is Professor of both disciplines at Harvard University. He is a 'founding father' of medical anthropology and has published widely, including Rethinking Psychiatry (Kleinman, 1988) and Patients and Healers in the Context of Culture: An Exploration of the Borderland Between Anthropology, Medicine and Psychiatry (Kleinman, 1980).

On 14 March 2016, IMAN co-hosted a meeting at the Royal College of Physicians of Ireland together with the RAMI Section of Epidemiology and Public Health, Centre for Global Health Trinity College Dublin and AAI. At this meeting Kleinman spoke about his new book, A Passion for Society. How We Think About Human Suffering, co-authored by Iain Wilkinson (Kleinman \& Wilkinson, 2016). Responses were given by anthropologists Jamie Saris and Ciara Kierans (from Maynooth and Liverpool universities, respectively), Patrick O'Sullivan, Fellow of the Faculty of Public Health Medicine of Ireland \& RAMI, and Iain Wilkinson, co-author and sociologist at the University of Kent. A report and comment on this meeting is available at http://globalhealth.ie/who-cares-careand-society-in-the-modern-world/.

The following day Kleinman was keynote speaker at the annual conference of the AAI at Maynooth University on 15 March 2016, talking to the theme of the conference 'Caring Cultures: Cultures of Care'. His observations reflect his multidisciplinary background together with personal experience, and resonate with the College of Psychiatrists of Ireland theme for 2014/ 2015 'Caring for carers'. A summary of the proceedings at the AAI conference will be available in a forthcoming edition of the Irish Journal of Anthropology.

\section{Developing links between anthropology and psychiatry}

New approaches are important to throw light on old intransigent problems, in clinical work with individual patients and for service development. New perspectives can help to develop novel solutions to complex problems. Anthropology offers a holistic approach which recognises different perspectives and addresses complexity. Skultans \& Cox (2000) recommend that 'crossing the bridge' between anthropology and psychiatry can benefit professional practice and research.

As individuals we are all unique, and, as clinicians, we know that each patient is unique. But practitioners also know that this uniqueness is shaped and coloured by where and how each individual lives, by the social setting he or she inhabits, and by people's beliefs and values. Our uniqueness as individuals is shaped and coloured by the society and culture in which we live, and cultures differ in more than language. The presentation and management of illness and disease, and the health services developed to cope with and improve the lot of individual patients, are influenced to varying degrees by cultural context, at both local and wider levels. Better understanding of the cultural similarities and differences between ourselves and our patients means better communication, which in turn means a more satisfactory experience for both patient and practitioner and, most importantly, better health outcomes (Stewart, 1995).

\section{Acknowledgements}

This paper is based on a presentation I gave to the Annual General Meeting of the College of Psychiatrists of Ireland on 4 March 2016 in Dublin. The presentation was the most recent of a series I have given to various groups of health professionals outlining what anthropology has to offer 'health'. In some countries the links between anthropology and medicine are more developed, but in Ireland there has been limited anthropological input to the education, research and practice of health professionals. Such input is relevant to all health professionals, regardless of speciality. Most of my working life was spent as a public health physician, latterly with special interest in the supply and quality of drinking water. But before medical education I studied and taught anthropology; my PhD was entitled "Folk medicine and faith healing in northern Ireland'. In the 1970s, at the time my career changed direction, in Ireland the disciplines were mutually exclusive. At different times during medical practice I found that my background in anthropology was more relevant than medical studies, but mostly I kept this observation to myself. Only later in my career did I return to anthropology and combine the knowledge and experience of both disciplines to teach 'Anthropological perspectives' in the 'Determinants of health' module on the MSc in Global Health course in Trinity College Dublin. More recently, in 2012, I gave an essentially reflective presentation to Public Health colleagues in the Royal College of Physicians and was gratified at the level of interest engendered. The potential for developing interdisciplinary links was apparent and since then I have been working with 
colleagues from various backgrounds to raise the awareness of the value of anthropology to 'health' and health professionals.

\section{Financial Support}

None.

\section{Conflicts of Interest}

None.

\section{Ethical Standards}

The author asserts that all procedures contributing to this work comply with the ethical standards of the relevant national and institutional committee on human experimentation with the Helsinki Declaration of 1975, as revised in 2008.

\section{References}

Helman CG (2007). Culture, Health and Illness, 5th edn. Hodder Arnold: London.

Kleinman A (1980). Patients and Healers in the Context of Culture: An Exploration of the Borderland Between Anthropology, Medicine and Psychiatry. University of California Press: Berkeley, CA.

Kleinman A (1988). Rethinking Psychiatry. Free Press: New York. Kleinman A, Wilkinson I (2016). A Passion for Society. How We Think About Human Suffering. University of California Press: Berkeley, CA.

Koss-Chionino J (1999). Integrating mental health care and traditional healing in Puerto-Rico: lessons from an early experiment. In Anthropology in Public Health. Bridging Differences in Culture and Society (ed. R. A. Hahn), pp. 279-299. Oxford University Press: New York.

Larkan F, van Wyk B, Stevens P, Saris AJ (2015). Between the clinic and the community: temporality and patterns of ART adherence in the Western Cape Province, South Africa. African Sociological Review 19, 26-52.
Moore R, McClean S (editors) (2010). Folk Healing and Healthcare Practices in Britain and Ireland. Berghahn Books: Oxford.

Pettigrew J (2007). Learning to be silent: change, childhood and mental health in the maoist insurgency in Nepal. In Nepalis Inside and Outside Nepal: Political and Social Transformations (Series: Japanese Studies on South Asia) (ed. H. Ishi, D. N. Gellner and K. Nawa), pp. 307-348. Manohar: New Delhi.

Saris AJ (1997). The asylum in Ireland: a brief institutional history and some local effects. In The Sociology of Health and Illness In Ireland (ed. A. Cleary and M. P. Treacy), pp. 208-223. University College Dublin Press: Dublin.

Saris AJ (2011). The addicted self and the pharmaceutical self: ecologies of will, information, and power in junkies, addicts and patients. In The Pharmaceutical Self: The Global Shaping of Experience in an Age of Psychopharmacology (ed. J. H. Jenkins), pp. 209-229. School for Advanced Research on the Human Experience: Santa Fe, NM.

Saris AJ (2013a). Committed to will: what's at stake for anthropology in addiction. In: Addiction Trajectories (ed. E. Raikhel and W. Garriott), pp. 263-283. Duke University Press: Durham, NC.

Saris AJ (2013b). Studying suicide in modern Ireland: new directions and old conundrums. Irish Journal of Anthropology 15, 6-7.

Shears P, O'Dempsey TJD (2015). Ebola virus disease in Africa: epidemiology and nosocomial transmission. Journal of Hospital Infection 90, 1-9.

Skultans V, Cox J (editors) (2000). Anthropological Approaches to Psychological Medicine: Crossing Bridges. Jessica Kingsley Publishers: London.

Stewart MA (1995). Effective physician-patient communication and health outcomes: a review. Canadian Medical Association Journal 152, 1423-1433.

World Health Organisation (2012). Communication for Behavioural Impact (COMBI). A Toolkit for Behavioural and Social Communication in Outbreak Response. World Health Organisation: Geneva.

Wilson TM, Donnan H (2006). The Anthropology of Ireland. Berg: Oxford. 